\title{
Sociodemographic profile of tobacco use and its predictors in Kerala, India
}

\author{
Ramanarayanan Venkitachalam ${ }^{1}$, Kavya Rajeev ${ }^{1}$
}

\section{AFFILIATION}

1 Department of Public Health Dentistry, Amrita School of Dentistry, Amrita Vishwa Vidyapeetham, Kochi, India

\section{CORRESPONDENCE TO}

Ramanarayanan Venkitachalam. Department of Public Health Dentistry, Amrita School of Dentistry, Amrita Vishwa Vidyapeetham, AIMS, Ponekkara PO, Kochi 682041 Kerala, India. E-mail: venkitr2006@gmail.com

\section{KEYWORDS}

tobacco, India, smoking tobacco, smokeless tobacco, sociodemographics Received: 15 June 2020, Revised: 15 September 2020, Accepted: 9 October 2020

https://doi.org/10.18332/popmed/128324

\begin{abstract}
INTRODUCTION The burden of tobacco use is high in India. Tobacco use behaviour is influenced by sociodemographic factors. The Indian state of Kerala is considered unique compared to the rest of India in having high social development indices. The objective of this study was to explore the sociodemographic factors affecting tobacco use and its predictors in Kerala.

METHODS A cross-sectional study was conducted using data obtained from the Global Adult Tobacco Survey 2 (20162017) for the state of Kerala in India. Questions from the survey pertaining to sociodemographic characteristics (age, gender, area of residence, marital status, religion, education level, and employment status) were selected and served as
\end{abstract}

independent variables. Outcomes are reported as odds ratios. RESULTS A total of 2186 individuals (783 men and 1403 women) participated in GATS- 2 of Kerala state. People aged $<45$ years were less likely to be smokers (OR=0.54; $95 \% \mathrm{CI}$ : $0.39-0.75)$ and smokeless tobacco users (OR=0.20; 95\% CI: $0.12-0.33)$. Men were more likely to use tobacco compared to women $(\mathrm{OR}=189.9$; 95\% CI: 46.95-768.10 for smoking tobacco, and OR=2.29; 95\% CI: $1.55-3.38$ for smokeless forms).

CONCLUSIONS Tobacco use in Kerala was below the national average. Older age ( $\geq 45$ years) was associated with tobacco use while poor literacy levels and employment status were significantly associated with smoking.

\section{INTRODUCTION}

It is estimated that there are almost 267 million tobacco users in India ${ }^{1}$. Tobacco is used in both smoking and smokeless forms with the latter being more prevalent. Though there has been a decline in the tobacco use from $34.6 \%$ in $2009-2010$ to $28.6 \%$ in $2016-2017^{2}$, the numbers still constitute a major burden. Every year, the mortality that has been attributed to tobacco use is close to a million, which is now projected to be 1.5 million by $2020^{3}$.

While tobacco use may seem an individual's choice or preference, the effect of social dynamics cannot be discounted 4 . Sociodemographic determinants have been known to influence health related behaviours, and tobacco use is no exception. It is proposed that tobacco use disproportionately affects people belonging to low socioeconomic status (SES) as they are influenced by marketing tactics, lack of awareness, access to cheap tobacco products, psychological stress etc ${ }^{5}$. The effect of SES has been reflected in the patterns of tobacco use, secondhand smoke exposure, quitting behaviour, and marketing strategies. Innovative marketing practices like packaging and promotion of tobacco products have been shown to differentially impact vulnerable populations ${ }^{4,6}$.

Kerala is a relatively small state in the southern peninsular region of India. Tobacco use in various forms including smoking and chewing has been an integral part of the social customs practiced there by several communities for centuries ${ }^{7}$. Kerala is regarded unique to other states in India in terms of having good health indicators. It is also a state with high indicators of social development. The state is presently dealing with the burden of non-communicable diseases with tobacco being a major modifiable risk factor ${ }^{3}$. Hence tobacco control and cessation are an important public health priority in the state.

The Global Adult Tobacco Survey (GATS) is an attempt towards conducting a representative nationwide survey on 
adult tobacco use and key tobacco control measures. The first round GATS survey was conducted in the period 2010-2011 and the latest was completed in the period 2016-2017.

The objective of this study was to explore the sociodemographic factors affecting tobacco use and its predictors in Kerala. An understanding of the sociodemographic factors affecting tobacco use can provide vital information that will help determine priorities and strategies for effective tobacco control and cessation programs.

\section{METHODS}

The study adopted a cross-sectional design. Data from the second Global Adult Tobacco Survey (GATS-2) conducted in India between 2016 and 2017 were analysed for the state of Kerala. The Global Adult Tobacco Survey (GATS), a component of Global Tobacco Surveillance System (GTSS), is a standardized global monitoring tool for tobacco use and its related indicators. It is performed on a nationally representative sample of adults aged $\geq 15$ years with a standardized questionnaire validated by experts. Data from GATS are intended to be used by countries for planning, implementing and evaluating tobacco control interventions ${ }^{8}$.

GATS-2 India was conducted in 2017 using a multistage stratified cluster sample design. The sample size was 84047 selected households with 74037 completed individual interviews ${ }^{9}$. A total of 2186 individuals (783 males and 1403 females) from Kerala participated in GATS-29.

Selected questions in the domains of tobacco smoking, e-cigarette use, smokeless tobacco use, other tobacco product use, cessation, secondhand smoke, economics, media, knowledge, attitudes and perceptions were considered as the dependent variables and sociodemographic characteristics such as age group, gender, area of residence, marital status, religion, education level, and employment status, were included as the independent variables.

All the dependent and independent variables with multiple responses were dichotomized. Median age was calculated and accordingly grouped, employment status was grouped as 'employed' and 'unemployed', education level was categorized as 'studied to less primary school' and 'studies up to primary school or above', and marital status was grouped as 'having a partner' and 'not having a partner' (single, divorced, widowed).

Data were analyzed using IBM SPSS Version 20 software for Windows. Differences in proportions between the independent and dependent variables were tested using Pearson's chi-squared test. Odds ratios were calculated and are reported.

\section{RESULTS}

A total of 2186 individuals (783 men and 1403 women) participated in GATS- 2 of Kerala state among which around $36 \%$ were men. About half (48.2\%) of the study population lived in urban areas while $17 \%$ did not have any formal schooling or had not completed primary schooling. Of the 2186 individuals, 169 (7.7\%) were current smokers, 109 (5\%) were smokeless tobacco users and 30 (1.3\%) used both. None of the participants reported to be using e-cigarettes. Among the smokers, more than $99 \%$ reported to use cigarettes. Use of bidis, hukkah, cigars, cheroots etc. was negligible $(<1 \%)$. Similarly, use of other forms of smokeless tobacco namely gutka, mawa, mishri, gudaku etc. was also very low.

Bivariate analysis was performed for independent sociodemographic predictors of tobacco use (age, gender, education level, employment status, marital status, and area of residence).

With regard to current tobacco use status, people aged $<45$ years were less likely to be smokers $(\mathrm{OR}=0.54$; $95 \% \mathrm{CI}$ : $0.39-0.75$ ) and smokeless tobacco users (OR=0.20; 95\% CI: $0.12-0.33$ ) whereas it was significantly more likely to be used by men (OR=189.9; 95\% CI: 46.95-768.10 for smoking, and $\mathrm{OR}=2.29$; $95 \% \mathrm{CI}: 1.55-3.38$ for smokeless forms) (Table 1). Having no formal or less than primary schooling increased the likelihood of using tobacco (OR=2.07; 95\% CI: $1.45-2.95$ for smoking, and OR=5.88; 95\% CI: 3.97-8.73 for smokeless tobacco) compared to people with formal schooling. Being employed increased the chances of smoking tobacco use by almost 9 times (OR=9.37; 95\% CI: 6.14-14.28) (Table 2). On comparison based on marital status, it was observed that married people were more likely to use smoking tobacco $(\mathrm{OR}=2.30$; 95\% CI: 1.45-3.64) while unpartnered individuals were less likely to use smokeless tobacco $(\mathrm{OR}=0.62 ; 95 \% \mathrm{CI}$ : $0.41-0.93)$. There was a statistically significant less likelihood of people dwelling in urban areas to use smokeless tobacco compared to their rural counterparts $(\mathrm{OR}=0.63 ; 95 \% \mathrm{CI}$ : $0.42-0.94)$. However, no significant differences were noted for smoking tobacco (OR=0.86; 95\% CI: 0.63-1.19) (Table 3).

Mean age of initiation of smokeless tobacco use among men was $34.94 \pm 19.59$ years while for women it was 32.07 \pm 21.94 years $(p=0.55)$. No significant differences were also noted for the effect of education status on age of onset for smoking (less than primary schooling $22.66 \pm 14.86$ years, women $24.36 \pm 12.19$ years; $\mathrm{p}=0.50$ ) and smokeless tobacco (less than primary schooling $30.77 \pm 21.83$ years, women $36.68 \pm 19.27$ years; $p=0.21$ ).

Although $43.8 \%$ of the smokers attempted to quit smoking in the last 12 months, there were no significant associations between quit attempts and any of the predictor variables.

Awareness regarding secondhand smoke was significantly higher among people aged $<45$ years and poor education status (OR=2.60; 95\% CI: 1.94-3.50) (Table 1). Awareness regarding the effects of smoking and smokeless tobacco on health were consistently higher among people aged $<45$ years (OR=3.02; 95\% CI: 2.02-4.50 for smoking, and OR=4.35; 95\% CI: 3.09-6.13 for smokeless tobacco) (Table 1) and lower among participants with lower education status (OR=0.14; 95\% CI: 0.10-0.21 for smoking, and OR=0.19; 95\% CI: $0.14-0.26$ for smokeless tobacco) (Table 2).

Compared with people who had completed primary 
Table 1. Association between tobacco use and behaviour with age group and gender, GATS ( $\mathrm{N}=2186)$

\begin{tabular}{|c|c|c|c|c|c|c|c|}
\hline & & \multicolumn{3}{|c|}{ Age group } & \multicolumn{3}{|c|}{ Gender } \\
\hline & Response & $\begin{array}{c}<45 \text { years } \\
n(\%)\end{array}$ & $\begin{array}{c}\geq 45 \text { years } \\
n(\%)\end{array}$ & OR $(95 \% \mathrm{CI})$ & $\begin{array}{l}\text { Men } \\
\text { n (\%) }\end{array}$ & $\begin{array}{l}\text { Women } \\
\text { n }(\%)\end{array}$ & OR $(95 \% \mathrm{CI})$ \\
\hline \multirow{2}{*}{$\begin{array}{l}\text { Current smoking } \\
\text { status }\end{array}$} & User & 65 (5.7) & $104(10.0)$ & \multirow{2}{*}{$0.54(0.39-0.75)$} & 167 (21.3) & $2(0.1)$ & \multirow{2}{*}{189.9 (46.95-768.1 } \\
\hline & Non-user & 1077 (94.3) & $940(90.0)$ & & 616 (78.7) & 1401 (99.9) & \\
\hline \multirow{2}{*}{$\begin{array}{l}\text { Current smokeless } \\
\text { tobacco use }\end{array}$} & User & 21 (1.8) & $88(8.4)$ & \multirow{2}{*}{$0.20(0.12-0.33)$} & 60 (7.7) & $49(3.5)$ & \multirow[t]{2}{*}{$2.29(1.55-3.38)$} \\
\hline & Non-user & $1121(98.2)$ & 956 (91.6) & & 723 (92.3) & 1354 (96.5) & \\
\hline \multirow{2}{*}{$\begin{array}{l}\text { Pan masala without } \\
\text { tobacco }\end{array}$} & User & $4(0.4)$ & $11(1.1)$ & \multirow{2}{*}{$0.33(0.10-1.04)$} & $12(1.5)$ & $3(0.2)$ & \multirow[t]{2}{*}{$7.26(2.04-25.81)$} \\
\hline & Non-user & 1138 (99.6) & 1033 (98.9) & & 771 (98.5) & 1400 (99.8) & \\
\hline \multirow{2}{*}{$\begin{array}{l}\text { Betel quid without } \\
\text { tobacco }\end{array}$} & User & $14(1.2)$ & $34(3.3)$ & \multirow{2}{*}{$0.36(0.19-0.69)$} & $20(2.6)$ & $28(2.0)$ & \multirow[t]{2}{*}{$1.2(0.72-2.3)$} \\
\hline & Non-user & 1128 (98.8) & 1010 (96.7) & & 763 (97.4) & 1375 (98.0) & \\
\hline \multirow{2}{*}{$\begin{array}{l}\text { During the past } \\
12 \text { months, have } \\
\text { you tried to stop } \\
\text { smoking? }\end{array}$} & Yes & $30(46.2)$ & 35 (42.3) & \multirow{2}{*}{$1.16(0.62-2.18)$} & 73 (43.7) & $1(50)$ & \multirow[t]{2}{*}{$0.77(0.04-12.62)$} \\
\hline & No & $44(54.8)$ & $60(57.7)$ & & $94(56.3)$ & $1(50)$ & \\
\hline \multirow{2}{*}{$\begin{array}{l}\text { Does breathing } \\
\text { other people's } \\
\text { smoke cause } \\
\text { serious illness in } \\
\text { non-smokers }\end{array}$} & Yes & 1070 (93.8) & $890(85.2)$ & \multirow{2}{*}{$2.60(1.94-3.50)$} & 711 (90.9) & 1249 (89) & \multirow[t]{2}{*}{$1.23(0.91-1.66)$} \\
\hline & $\begin{array}{l}\text { No/don't } \\
\text { know }\end{array}$ & $71(6.2)$ & 154 (14.8) & & $71(9.1)$ & $154(11.0)$ & \\
\hline \multirow{2}{*}{$\begin{array}{l}\text { Does smoking } \\
\text { tobacco cause } \\
\text { serious illness }\end{array}$} & Yes & 1106 (96.9) & 951 (91.3) & \multirow[t]{2}{*}{$3.02(2.02-4.50)$} & $738(94.4)$ & 1319 (94.1) & \multirow[t]{2}{*}{$1.04(0.71-1.52)$} \\
\hline & $\begin{array}{l}\text { No/don't } \\
\text { know }\end{array}$ & $35(3.1)$ & $91(8.7)$ & & $44(5.6)$ & 82 (5.9) & \\
\hline \multirow{2}{*}{$\begin{array}{l}\text { Does smokeless } \\
\text { tobacco cause } \\
\text { serious illness }\end{array}$} & Yes & $1096(96.1)$ & $884(84.8)$ & \multirow{2}{*}{4.35 (3.09-6.13) } & 736 (94.1) & 1282 (92.5) & \multirow[t]{2}{*}{$1.48(1.04-2.11)$} \\
\hline & $\begin{array}{l}\text { No/don't } \\
\text { know }\end{array}$ & 45 (3.9) & $158(15.2)$ & & $46(5.9)$ & 119 (8.5) & \\
\hline \multirow{2}{*}{$\begin{array}{l}\text { Does smoking } \\
\text { tobacco cause lung } \\
\text { cancer }\end{array}$} & Yes & 1097 (96.1) & $921(88.4)$ & \multirow[t]{2}{*}{3.27 (2.29-4.67) } & 703 (89.9) & 1277 (91.1) & \multirow[t]{2}{*}{$0.86(0.64-1.16)$} \\
\hline & $\begin{array}{l}\text { No/don't } \\
\text { know }\end{array}$ & 44 (3.9) & $121(11.6)$ & & 79 (10.1) & 124 (8.9) & \\
\hline \multirow{2}{*}{$\begin{array}{l}\text { Does smokeless } \\
\text { tobacco use cause } \\
\text { oral cancer }\end{array}$} & Yes & 1085 (95.1) & 895 (85.9) & \multirow[t]{2}{*}{$3.18(2.31-4.38)$} & $708(90.5)$ & $1272(90.8)$ & \multirow[t]{2}{*}{$0.97(0.71-1.31)$} \\
\hline & $\begin{array}{l}\text { No/don't } \\
\text { know }\end{array}$ & $56(4.9)$ & $147(14.1)$ & & $74(9.5)$ & $129(9.2)$ & \\
\hline \multirow{2}{*}{$\begin{array}{l}\text { Does tobacco use } \\
\text { lead to addiction }\end{array}$} & Yes & 1032 (90.4) & $850(81.6)$ & $2.13(1.66-2.75)$ & 638 (81.6) & 1244 (88.8) & $0.55(0.43-0.71)$ \\
\hline & $\begin{array}{l}\text { No/don't } \\
\text { know }\end{array}$ & 109 (9.6) & $192(18.4)$ & & $144(18.4)$ & 157 (11.2) & \\
\hline
\end{tabular}

Table 2. Association between tobacco use and behaviour with education level and employment status, GATS $(\mathrm{N}=\mathbf{2 1 8 6})$

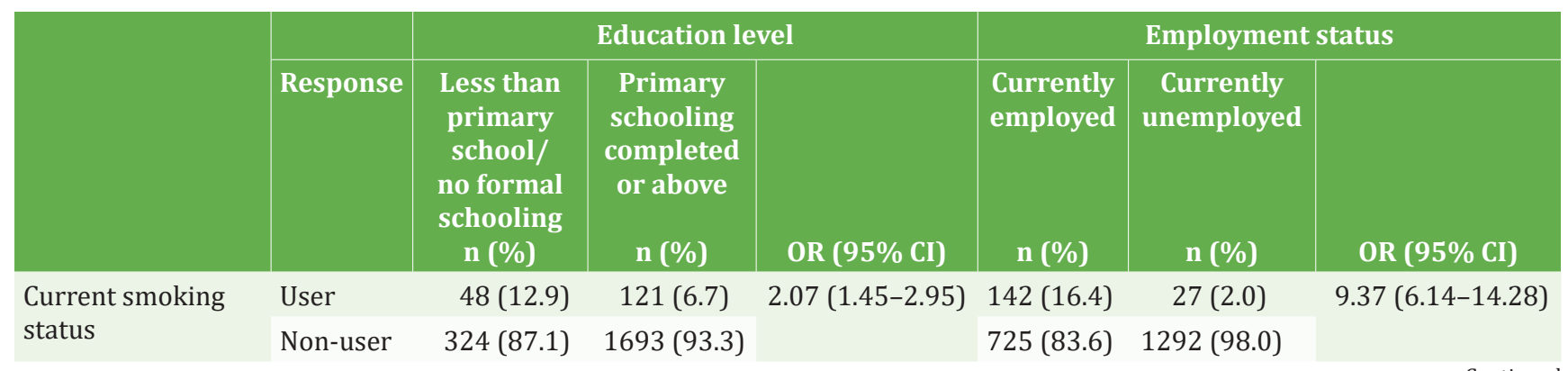


Table 2. Continued

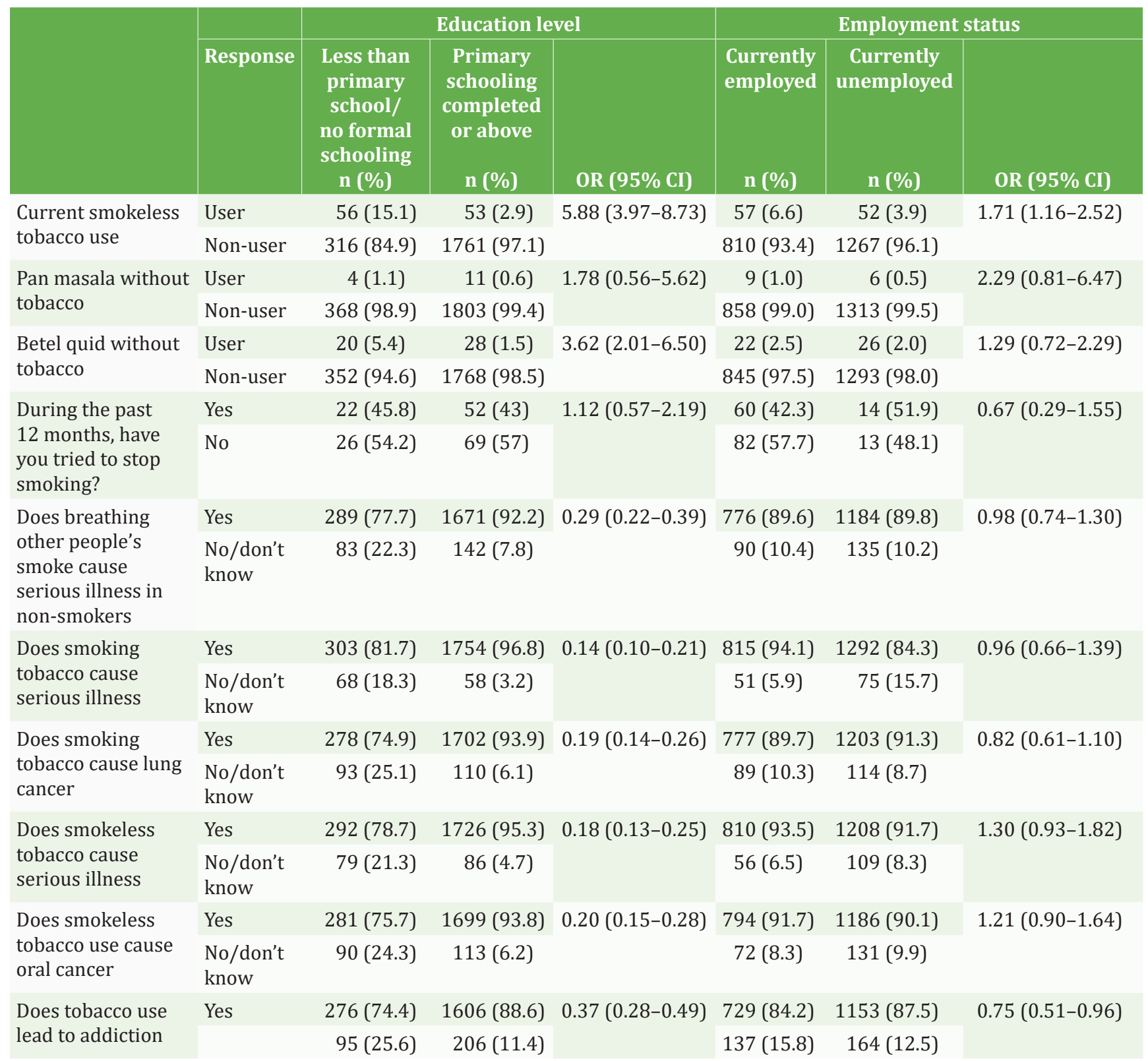

Table 3. Association between tobacco use and behaviour with marital status and area of residence

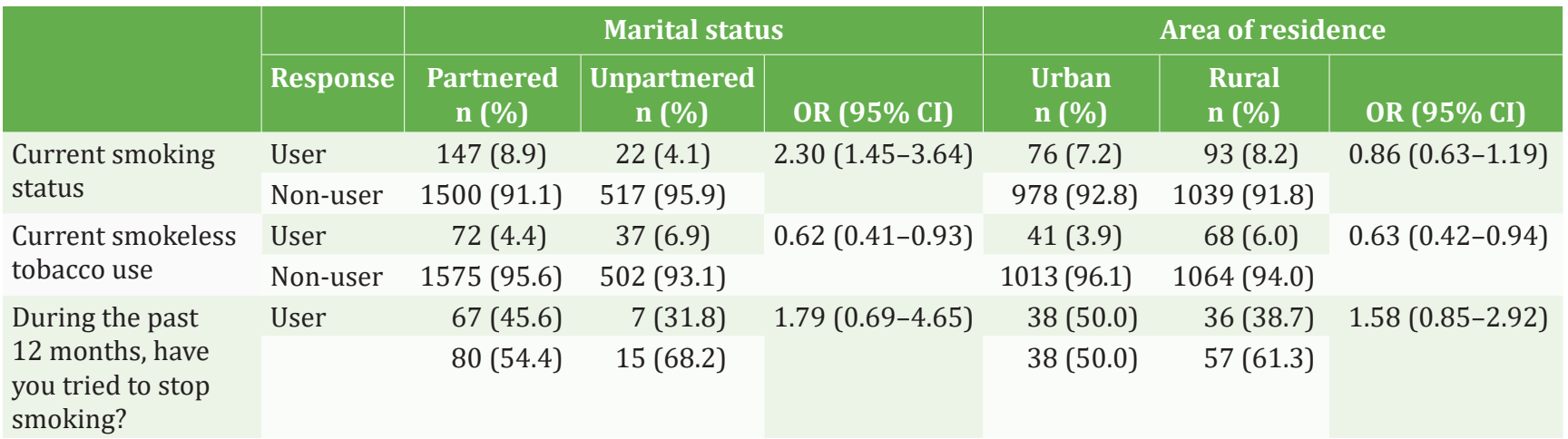


schooling, respondents who had less than primary school or no formal education were less likely to notice health warnings on cigarette packs (OR $=0.47 ; 95 \% \mathrm{CI}: 0.35-0.63)$ and smokeless tobacco products (OR=0.52; 95\% CI: 0.37-0.73).

\section{DISCUSSION}

Data from previous epidemiological studies have documented the role of sociodemographic factors in tobacco use behaviour ${ }^{10,11}$. This study assessed the influence that they have on the individual's tobacco use behaviour. The findings would be useful in directing various campaigns and programmes against tobacco usage to the most vulnerable groups. The use of a standard questionnaire facilitated worthy comparisons. Smoking tobacco use was found to be $7.7 \%$, which is less than the national average of $10.7 \%$, while smokeless tobacco use accounted for $5 \%$, which was considerably less than the national average of $21.5 \%{ }^{2}$.

The state of Kerala has the highest literacy rate in India. It is generally agreed that the fewer the years of education, the more likely a person is a smoker. This study observes that poor education has significant association with tobacco use behaviour, age of tobacco use initiation, awareness regarding secondhand smoke, and knowledge of the detrimental health effects of tobacco. These findings are in tune with other representative sample and national surveys ${ }^{10,12-14}$. A study done in rural Gujarat observed that people with elementary and high school education levels consumed more tobacco compared to individuals with no formal education or college degree ${ }^{15}$. However, in the present study, education level was dichotomized, which meant all individuals above elementary (primary) education were considered as a single entity. Similar findings were also noted with betel quid with tobacco. 'Supari', as it is referred to in local parlance, was also found to have an educational differentiation in its usage ${ }^{16}$.

Older individuals ( $\geq 45$ years) were more likely to use any forms of tobacco and were less likely to be aware of secondhand smoke effects. However, based on the results of National Family Health Survey-2 (1998-1999), the prevalence of tobacco consumption initially increased till the age of 50 years, and later declined ${ }^{10}$. An analysis of the GATS- 1 conducted in 2010 showed that smoking was highest in the age group 50-54 years, which is in agreement with the findings of the present study ${ }^{11}$. The use of betel quid without tobacco was also significantly higher in people aged $\geq 45$ years. This observation could probably be attributed to the cultural practice of using betel quid among the older generation in India ${ }^{17}$.

Tobacco use behaviour (both smoking and smokeless tobacco use) was significantly higher among men. This observation was expected as smoking among women is considered a taboo in Indian communities. Hence, the reporting of smoking by women could probably have been low. Comparatively higher percentage of women reported using smokeless tobacco as it is relatively acceptable in the Indian society ${ }^{18}$. While there was no statistically significant difference in the perception of men and women with regard to smoking causing serious illness, awareness regarding smokeless tobacco use causing serious illness was significantly higher among men. However, the proportion of men and women who believed tobacco use causes serious illness was high $(>90 \%)$ for both smoking and smokeless forms. A study done in Pakistan reports that both men and women thought smokeless tobacco use was less harmful than smoking ${ }^{19}$. Being employed was associated with higher chances of tobacco use, as was observed in similar studies. While some studies report that unemployment was a predictor for tobacco use ${ }^{20}$, few analysed the various categories of occupations and their association with the forms of tobacco use $\mathrm{e}^{14,21}$.

The urban rural differentiation was found to be significantly different in smokeless tobacco use. This is in accordance with the normative assumption that rural households use smokeless forms of tobacco where the effect of culture is still ingrained in daily living ${ }^{14}$. Lack of a significant difference in smoking tobacco use could be due to the fact that the type of smoking product was not considered. Many studies have shown a rural predilection for bidi smoking while cigarette smoking was commonly found among the urban strata ${ }^{13,22}$.

Quitting tobacco use was not found to have a significant association with any of the sociodemographic variables under consideration. This is in stark contrast to the studies done using national level GATS-1 survey, which showed strong associations with age, gender and education level among other factors $^{23,24}$. The variations in the categorization of variables between the studies could have impacted the results.

\section{Strengths and limitations}

Among the strengths of the study is the use of a representative sample of the state of Kerala from the GATS survey of 2017. The study was, however, not without its limitations. Dependent variables and predictors were dichotomized for the purpose of calculating risk ratios, thus this study had its limitation in not considering categories of occupations rather than the dichotomized employed/ unemployed status, due to limited data. Being a self-reported questionnaire, effect of information bias, recall bias and social desirability, to name a few, could not be ruled out.

\section{CONCLUSIONS}

The effects of sociodemographic variables (age, gender, area of residence, education level, and area of residence) were found to be associated with tobacco use behaviour in the Indian state of Kerala. Older age ( $\geq 45$ years) was associated with tobacco use while poor literacy levels (less than primary schooling) and employment were significantly associated with smoking tobacco. Rural populations were more likely to use smokeless tobacco. However, the prevalence of smoking $(7.7 \%)$ and smokeless tobacco use $(1.3 \%)$ in Kerala was below the national average of $10.7 \%$ and $21.5 \%$, respectively. 


\section{REFERENCES}

1. The Toll of Tobacco in India. Campaign for Tobacco-Free Kids. https://www.tobaccofreekids.org/problem/toll-global/asia/ india. Updated January, 2018. Accessed September 15, 2020.

2. GATS 2 (Global Adult Tobacco Survey) Fact Sheet, India, 2016-17. World Health Organization. https://www.who. int/tobacco/surveillance/survey/gats/GATS_India_2016-17_ FactSheet.pdf?ua=1. Updated October, 2017. Accessed September 15, 2020.

3. Thankappan KR, Thresia CU. Tobacco use \& social status in Kerala. Indian J Med Res. 2007;126(4):300-308. PMID:18032805.

4. Priya M, Harry AL, Sigamani P. Assessment of Tobacco Consumption and Control in India. Indian Journal of Clinical Medicine. 2018;9:1-8. doi:10.1177/1179916118759289

5. Hitchman SC, Fong GT, Zanna MP, Thraser JF, Chung-Hall J, Siahpush M. Socioeconomic Status and Smokers' Number of Smoking Friends: Findings from the International Tobacco Control (ITC) Four Country Survey. Drug Alcohol Depend. 2014;143:158-166. doi:10.1016/j.drugalcdep.2014.07.019

6. Bhan N, Karan A, Srivastava S, Selvaraj S, Subramanian SV, Millett C. Have Socioeconomic Inequalities in Tobacco Use in India Increased Over Time? Trends From the National Sample Surveys (2000-2012). Nicotine Tob Res. 2016;18(8):1711-1718. doi:10.1093/ntr/ntw092

7. Kyaing NN, Islam MA, Sinha DN, Rinchen S. Social, economic and legal dimensions of tobacco and its control in South-East Asia region. Indian J Public Health. 2011;55(3):161-168. doi:10.4103/0019-557x.89944

8. Global Adult Tobacco Survey (GATS). World Health Organization. http://www.who.int/tobacco/surveillance/ survey/gats/en/. Accessed September 15, 2020.

9. Global Tobacco Surveillance System (GTSSData). Centers for Disease Control and Prevention. https://nccd.cdc. gov/GTSSDataSurveyResources/Ancillary/DataReports. aspx?CAID=2. Accessed September 15, 2020.

10. Rani M, Bonu S, Jha P, Nguyen SN, Jamjoum L. Tobacco use in India: prevalence and predictors of smoking and chewing in a national cross sectional household survey. Tob Control. 2003;12(4):e4. doi:10.1136/tc.12.4.e4

11.Singh A, Ladusingh L. Prevalence and Determinants of Tobacco Use in India: Evidence from Recent Global Adult Tobacco Survey Data. PLoS One. 2014;9(12):e114073. doi:10.1371/journal.pone.0114073

12. Sharma D, Goel S, Lal P. Education differential in relation to tobacco use and its predictors across different regions of India. Indian J Cancer. 2017;54(3):584-588. doi:10.4103/ijc.ijc_345_17 13. Gupta V, Yadav K, Anand K. Patterns of Tobacco Use Across

\section{CONFLICTS OF INTEREST}

The authors have completed and submitted the ICMJE Form for Disclosure of Potential Conflicts of Interest and none was reported.

\section{FUNDING}

There was no source of funding for this research.
Rural, Urban, and Urban-Slum Populations in a North Indian Community. Indian J Community Med. 2010;35(2):245-251. doi:10.4103/0970-0218.66877

14. Singh A, Arora M, English DR, Mathur MR. Socioeconomic Gradients in Different Types of Tobacco Use in India: Evidence from Global Adult Tobacco Survey 2009-10. Biomed Res Int. 2015;837804. doi:10.1155/2015/837804

15. Kahar P, Misra R, Patel TG. Sociodemographic Correlates of Tobacco Consumption in Rural Gujarat, India. Biomed Res Int. 2016;5856740. doi:10.1155/2016/5856740

16. Arora M, Shrivastava S, Mishra VK, Mathur MR. Use of Betel Quid in India from 2009 to 2017: An Epidemiological Analysis of the Global Adult Tobacco Survey (GATS). Subst Use Misuse. 2020;55(9):1465-1471. doi:10.1080/1082608 4.2020 .1726393

17. Verma S. Areca nut (betel nut) chewing: a popular Indian cultural practice and its mucosal implications. Int J Dermatol. 2011;50(2):229-232. doi:10.1111/j.1365-4632.2010.04710.x

18. Ruhil R. India has reached on the descending limb of tobacco epidemic. Indian J Community Med. 2018;43(3):153-156. doi:10.4103/ijcm.IJCM_213_17

19. Iqbal N, Awan S, Riaz U, et al. Difference in gender perception regarding smokeless tobacco consumption; A cross sectional survey from Karachi Pakistan. Eur Respir J. 2019;54(suppl 63). doi:10.1183/13993003.congress-2019.PA706

20. Prabhakar B, Narake SS, Pednekar MS. Social disparities in tobacco use in India: The roles of occupation, education and gender. Indian J Cancer. 2012;49(4):401-409. doi:10.4103/0019-509x.107747

21. Shah S, Dave B, Shah R, Mehta TR, Dave R. Socioeconomic and cultural impact of tobacco in India. J Family Med Prim Care. 2018;7(6):1173-1176. doi:10.4103/jfmpc.jfmpc_36_18

22. Duong ML, Rangarajan S, Zhang X, et al. Effects of bidi smoking on all-cause mortality and cardiorespiratory outcomes in men from south Asia: an observational community-based substudy of the Prospective Urban Rural Epidemiology Study (PURE). Lancet Glob Health. 2017;5(2):e168-176. doi:10.1016/s2214-109x(17)30004-9

23. Srivastava S, Malhotra S, Harries AD, Lal P, Arora M. Correlates of tobacco quit attempts and cessation in the adult population of India: secondary analysis of the Global Adult Tobacco Survey, 2009-10. BMC Public Health. 2013;13:263. doi:10.1186/1471-2458-13-263

24. Reddy MM, Kanungo S, Naik BN, Kar SS. Willingness to quit tobacco smoking and its correlates among Indian smokers - Findings from Global Adult Tobacco Survey India, 20092010. J Family Med Prim Care. 2018;7(6):1353-1360. doi:10.4103/jfmpc.jfmpc_169_18

\section{PROVENANCE AND PEER REVIEW}

Not commissioned; externally peer reviewed. 